\title{
Short Term Outcome of Preterm Neonates Required Mechanical Ventilation
}

\author{
Md Abdul Mannan ${ }^{1 *}$ \\ Nasim Jahan ${ }^{1}$ \\ Shahed lqbal ${ }^{2}$ \\ Navila Ferdous ${ }^{1}$ \\ Subir Dey ${ }^{1}$ \\ Tashmin Farhana \\ Nondita Nazma ${ }^{3}$
}

'Department of Neonatology Ad-din Medical College Hospital Dhaka, Bangladesh.

${ }^{2}$ Department of Pediatrics

Chattagram Maa Shishu-O-General Hospital Chittagong, Bangladesh.

${ }^{3}$ Department of Pediatrics International Medical College \& Hospital Tongi, Dhaka.

\section{*Correspondence to:}

\section{Dr. Md. Abdul Mannan}

Associate Professor

Department of Neonatology

Ad-din Medical College Hospital

Dhaka, Bangladesh.

Mobile : +8801957322784

E-mail.dr_amannan@yahoo.com

\begin{abstract}
Background: Since its inception, the neonatal mechanical ventilator has been considered an essential tool for managing preterm neonates with Respiratory Distress Syndrome (RDS) and is still regarded as an integral component in the neonatal respiratory care continuum. Mechanical ventilation of newborn has been practiced for several years with several advances made in the way. As compared to the western world and neighboring countries, neonatal ventilation in our country is still in its infancy. To analyze the common indications and outcome of preterm neonates required mechanical ventilation. Methods: This was a retrospective observational study conducted on preterm neonates required mechanical ventilation over a period of 12 months (July 2013 to June 2014). Results: A total of 50 neonates were mechanically ventilated during the study period of which $68 \%(n=34)$ survived. The survival rate was higher (77\%) in 34- $<37$ weeks Gestational Age (GA) group and gradually declined in $30-<34$ weeks $(71 \%) \& 27-<30$ weeks $(56 \%)$ GA. The neonates with Birth Weight (BW) $\geq 2500$ gm were higher survivals which was $100 \%$ and lower in 1500-2499gm (81\%), 1000-1499gm (68\%) and 800-999gm (33\%) BW groups. Inborn neonates $(68 \%)$ showed marginally higher survivals than outborn $(66 \%)$ and also more survivals observed in preterm baby girls $(72 \%)$ than boys $(65 \%)$. RDS $(62 \%)$ was the commonest indication for ventilation followed by Neonatal Sepsis (14\%), Perinatal Asphyxia (PNA-10\%), Congenital Pneumonia $(8 \%)$ and Pneumothorax (6\%). And found higher survivals in RDS (77\%) than other indications which were in Pneumothorax (66\%), PNA (60\%), Sepsis (57\%) and Pneumonia $(50 \%)$. RDS $(n=31)$ with surfactant therapy $(n=14)$ recovered earlier $<7$ days $(71.43 \%)$ than non surfactant therapy neonates $(n=17)$, they required prolonged ventilator support over 7days (82.35\%). Conclusions: Mechanical ventilation reduces the neonatal mortality, hence facilities for neonatal ventilation should be included in the regional and central hospitals providing intensive care for neonates.
\end{abstract}

Key words: Preterm; Birth weight; Mechanical ventilation.

\section{INTRODUCTION}

Worldwide, about 15 million neonates are born at preterm each year ${ }^{1}$. Technological advances including mechanical ventilation play a major role in the survival of preterm neonates. The introduction of mechanical ventilation in the 1960 s was one of the major new interventions in neonatology, which provided life-saving support for infants with cardiorespiratory failure. Along with other technologic advancements, such as the administration of antepartum steroid, replacement of surfactant, nCPAP and mechanical ventilation has led to improved neonatal survival, especially for premature neonates ${ }^{2}$. 
RDS contributes to morbidity and mortality in preterm neonates mostly in developing countries ${ }^{1-3}$. Mortality of preterm neonates is higher compared to those in the developed countries. Use of ventilator and surfactant therapy improves respiratory status, decreases hospitalization and overall outcome. The advent of surfactant therapy has decreased the morbidity and mortality rate from RDS by approximately $50 \%{ }^{4-8}$. Infant mortality caused by RDS in the United States decreased from approximately 268 in 100,000 live births in 1971 to 98 in 100,000 live births in 1985 to 17 in 100,000 live births in $2007^{9,10}$. As compared to the western world and neighboring countries, the infrastructure and expertise to ventilate newborn is lacking in majority of our hospitals. The current study was planned to assess and share our experience of ventilator use and find out the indications and outcome of pre mature neonates required mechanical ventilation.

\section{MATERIALS AND METHODS}

A retrospective study was carried out in Neonatal Intensive Care Unit (NICU) of Ad-din Hospital, over 12 months from July 2013 to June 2014.

\section{Inclusion Criteria}

There were 400 NICU admissions during this period of which those preterm, 27 to $<37$ weeks GA \& BW 800 gm to 3500 gm consecutively placed on ventilator enrolled in the study.

\section{Exclusion criteria}

i) Term neonates $>37$ weeks

ii) Preterm $<27$ weeks

iii) Birth weight $<800 \mathrm{gm}$

iv) those babies having major, surgically uncorrectable lethal anomalies.

Over this period total 50 preterm neonates were enrolled and classified according to GA, BW, Gender and Place of delivery. A brief note of antenatal and natal history was taken from mothers. A pretested preformed was used to record intricate details of each patient. Written consent from parents of neonates was taken in each cases and permission of ethical review committee of Ad-din Medical College Hospital was also taken. After proper cleaning the collected data were analyzed thoroughly. Descriptive analyses were performed, differences in outcome by gender, BW, GA, disease diagnosis, duration of ventilation were determined using analysis of variance. Analyses were performed using the Statistical Package for Social Sciences (SPSS) version 12.

All admitted neonates were subjected to an Arterial Blood Gas Analysis (ABG) Chest X-Ray (CXR) along with a set of investigations to look for pulmonary abnormalities (eg. RDS, Pneumonia, Pneumothorax etc) infections, renal function, hyperbilirubinaemia and other biochemical abnormalities. Neonates were kept on SLE-5000/ SLE-4000 ventilator in PTV (Patient Triggered Ventilation) / SIMV (Synchronized Intermittent Mandatory Ventilation) mode and observed at the time of initiation of ventilation include Respiratory Rate (RR), Peak Inspiratory Pressure (PIP), Positive End Expiratory Pressure (PEEP), Fraction of Inspired Oxygen $\left(\mathrm{FiO}_{2}\right)$, Inspiratory time (Ti) and follow up $\mathrm{ABG}$ after 30 minutes of ventilation. Oxygen saturation $\left(\mathrm{SpO}_{2}\right)$ was monitored and maintained between $88-92 \%$ in $27-<32$ weeks, $90-<95 \%$ between $>32-<35$ weeks, $>95 \%-98 \%$ between $36-<37$ weeks GA. Complications encountered during ventilation and duration of ventilation was also noted. High Frequency Oscillatory Ventilator (HFOV- SLE 5000) also placed the neonates those failed conventional ventilator, Oxygenation Index (OI) $>40$ and had pneumothorax (After insertion of chest tube) and observed I: E ratio, frequency $(\mathrm{Hz})$, Mean Airway Pressure (MAP), delta $\mathrm{P}, \mathrm{FiO}_{2}$ and did follow up CXR and blood gas after one hour to see blood gas status and lung inflation. The objective was to ventilate the neonates effectively maintained normal ABGs with minimal work of breathing. All the ventilated neonates were nursed under servo controlled open incubator system. They were continuously under cardiac monitor (Drager) for heart rate, respiratory rate, temperature, ECG, Non Invasive Blood Pressure (NIBP) and oxygen saturation. They were diagnosed by preset criteria for Perinatal asphyxia (Failure to initiate and sustain breathing at birth), postnatal ABG noted profound metabolic or mixed acidemia- $\mathrm{p}^{\mathrm{H}}<7.1$ \& base deficit $>16$ $\mathrm{mmol} / \mathrm{L}$ within one hour of birth, APGAR score $0-3$ beyond 5 minutes, neonatal neurological sequale eg. seizures, stupor, coma, hypotonia and multiple organ involvement eg. lungs, heart, kidneys, liver, intestine, those were outborn came 6-12 hours after birth, ABG showed respiratory alkalosis $\mathrm{PCO}_{2}<20$ $25 \mathrm{mmHg}$, RDS (Preterm neonates presented with respiratory distress) worsen during first few hours of life which was progress over 48-72 hrs, ABG values- $\mathrm{p}^{\mathrm{H}}-<7.20, \mathrm{PCO}_{2}->$ $60 \mathrm{mmHg}, \mathrm{PO}_{2}<50 \mathrm{mmHg}$ or targeted oxygen saturation $<88 \%-90 \%$ in relation to $\mathrm{GA}$ with $\mathrm{FiO}_{2}>0.4$ under oxyhood (Measured by oxygen monitor) or oxyblender, CXR evidence of fine reticular granularity of the parenchyma, air bronchogram, diffuse mottling and bilateral confluent opaciation of lungs). Congenital pneumonia (X-ray evidence of consolidation) and Pneumothorax (X-ray evidence of air leak). The indications for ventilation were:

i) Severe respiratory distress with failure to maintain arterial blood gases by oxyblender $\mathrm{FiO}_{2}$ of $0.6-0.8$ ( $\mathrm{pH}<7.20$ and/or $\mathrm{PaCO}_{2}>60 \mathrm{mmHg}$ and/or $\mathrm{PaO}_{2}<50 \mathrm{mmHg}$ ).

ii) Failure to maintain targeted oxygen saturation $(>88 \%$ 90\%) with an $\mathrm{FiO} 20.4$ to 0.7 and had $\mathrm{PaCO}_{2}>60 \mathrm{mmHg}$ and/or $\mathrm{PaO}_{2}<50 \mathrm{mmHg}$ on nCPAP of 5-7 $\mathrm{cm} \mathrm{H}_{2} \mathrm{O}$ pressure.

iii) Persistent/recurrent severe apnea.

iv) Severe chest retraction, indrawing and/or gasping respiration.

Finally, outcome and duration of hospital stay were recorded. Septic screening was done in all neonates. Follow up investigations including serum electrolytes, blood urea, serum creatinine, random blood sugar and CXR were done. 


\section{RESULTS}

A total of 50 preterm neonates were mechanically ventilated. There were 32 males \& 18 females (Ratio 1.8:1). The mean BW was $1490 \mathrm{~g}$ (800-3500g) \& GA was 31.4 weeks (27$36 \mathrm{wks})$. Out of 50 neonates, $68 \%(\mathrm{n}=34)$ survived. Table 1 showed the survival of ventilated neonates in relation to BW, GA, Place of delivery \& Gender. The maximum number of ventilated neonates was in the group of weighing 1000 to 1499 gm $(44 \%) \& 30$ to $<34$ week (42\%) GA. Neonates of $>34-<$ 37 weeks had higher survival, $77 \%$ in comparison to $30-<34$ weeks $(71 \%)$ and $27-<30$ weeks $(56 \%)$ of GA. Preterm BW $>2500-3500$ gm was observed $100 \%$ survival \& $81 \%$, $68 \%$, and $33 \%$ in 1500- 2499gm, 1000-1499gm \& 800$999 \mathrm{gm}$ BW groups respectively. Survival of inborn marginally higher than out born, it was $68 \% \mathrm{vs} .66 \%$ \& preterm baby girls (72\%) showed higher than boys (65\%).

Table 2 showed the indications for mechanical ventilation and survival in different clinical conditions. RDS contributed to the maximum, it was $62 \%$, followed by Neonatal sepsis $14 \%$, PNA 10\%, Congenital Pneumonia 8\% \& Pneumothorax $6 \%$. Survival rate was highest in neonate required mechanical ventilation for RDS (77\%) and lowest among neonates with congenital pneumonia (50\%). Others like pneumothorax, PNA and Neonatal sepsis were $66 \%, 60 \%$ and $57 \%$ respectively. Table 3 showed RDS $(n=31)$ with surfactant therapy $(n=14)$ recovered earlier $<7$ days $(71.43 \%)$ than non surfactant therapy neonates $(\mathrm{n}=17)$, they required prolonged ventilator support over 7 days $(82.35 \%)$. Table 4 showed the ventilator associated complications like Ventilator Associated Pneumonia (14\%), Pneumothorax (12\%), Sepsis (10\%), Intraventricular hemorrhage $(8 \%)$, Bronchopulmonary dysplasia $(6 \%)$ \& Pulmonary Hemorrhage (4\%). Table 5 showed outcome of conventional ventilator higher than HFOV, it was $69 \%$ vs $63 \%$.

Table 1: Distribution of the ventilated neonate by baseline characteristics $(\mathrm{n}=50)$.

\begin{tabular}{lrrr}
$\begin{array}{l}\text { Gestational } \\
\text { Age (Wks) }\end{array}$ & Survival (\%) & Expired (\%) & Total (n=50) \\
$27-<30$ & $9(56 \%)$ & $7(44 \%)$ & $16(32 \%)$ \\
$30-<34$ & $15(71 \%)$ & $6(29 \%)$ & $21(42 \%)$ \\
$34-<37$ & $10(77 \%)$ & $3(23 \%)$ & $13(26 \%)$ \\
Weight & & & \\
$800-999$ & $3(33 \%)$ & $6(66 \%)$ & $9(18 \%)$ \\
$1000-1499$ & $15(68 \%)$ & $7(32 \%)$ & $22(44 \%)$ \\
$1500-2499$ & $13(81 \%)$ & $3(19 \%)$ & $16(32 \%)$ \\
$2500-3500$ & $3(100 \%)$ & 0 & $3(2 \%)$ \\
Place of delivery & & & \\
In born & $28(68 \%)$ & $13(31 \%)$ & $41(82 \%)$ \\
Out born & $6(66 \%)$ & $3(34 \%)$ & $9(18 \%)$ \\
Sex & & & \\
Male & $21(65 \%)$ & $11(35 \%)$ & $32(64 \%)$ \\
Female & $13(72 \%)$ & $5(28 \%)$ & $18(36 \%)$ \\
\hline
\end{tabular}

Table 2 : Distribution of outcome of neonates who were ventilated by diagnosis.

\begin{tabular}{lrrr}
$\begin{array}{l}\text { Reason for } \\
\text { ventilation }\end{array}$ & Survival (\%) Expired (\%) & Total \\
$\begin{array}{l}\text { Respiratory } \\
\text { distress syndrome }\end{array}$ & $24(77 \%)$ & $7(23 \%)$ & $31(62 \%)$ \\
$\begin{array}{l}\text { Perinatal asphyxia } \\
\text { Congenital }\end{array}$ & $3(60 \%)$ & $2(40 \%)$ & $5(10 \%)$ \\
Pneumonia & $2(50 \%)$ & $2(50 \%)$ & $4(8 \%)$ \\
Neonatal Sepsis & $4(57 \%)$ & $3(43 \%)$ & $7(14 \%)$ \\
Pneumothorax & $2(66 \%)$ & $1(33 \%)$ & $3(6 \%)$ \\
Total & $34(68 \%)$ & $16(32 \%)$ & $50(100 \%)$ \\
\hline
\end{tabular}

Table 3 : Duration of ventilator support with neonates of $\operatorname{RDS}(n=31)$.

\begin{tabular}{lrr}
$\begin{array}{l}\text { Duration of } \\
\text { Ventilator support }\end{array}$ & $\begin{array}{r}\text { RDS with } \\
\text { Surfactant }\end{array}$ & $\begin{array}{r}\text { RDS without } \\
\text { surfactant }\end{array}$ \\
D1-7 days & $10(71.43 \%)$ & $03(17.65 \%)$ \\
$>7$ days & $04(28.57 \%)$ & $14(82.35 \%)$ \\
TOTAL $(\mathrm{n}=31)$ & $14(100 \%)$ & $17(100 \%)$ \\
\hline
\end{tabular}

Table 4 : Outcome of neonates ventilated in the NICU by complications.

\begin{tabular}{lrrr} 
Complication & Survived & Expired & Total \\
Pneumonia & $6(85.7 \%)$ & $1(14.3 \%)$ & $7(14 \%)$ \\
Pneumothorax & $3(50 \%)$ & $3(50 \%)$ & $6(12 \%)$ \\
Neonatal Sepsis & $3(60 \%)$ & $2(40 \%)$ & $5(10 \%)$ \\
$\begin{array}{l}\text { Pulmonary } \\
\text { Hemorrhage }\end{array}$ & $1(50 \%)$ & $1(50 \%)$ & $2(4 \%)$ \\
$\begin{array}{l}\text { Intraventricular } \\
\text { Hemorrhage }\end{array}$ & $1(25 \%)$ & $3(75 \%)$ & $4(8 \%)$ \\
$\begin{array}{l}\text { Bronchopulmonary } \\
\text { Displasia }\end{array}$ & $3(100 \%)$ & 0 & $3(6 \%)$ \\
\hline
\end{tabular}

Table 5 : Type of ventilation \& outcome.

\begin{tabular}{lccc} 
Type of Ventilator & Survived & Expired & Total \\
Conventional & $29(69 \%)$ & $13(31 \%)$ & $42(100 \%)$ \\
HFOV (SLE-5000) & $05(63 \%)$ & $03(37 \%)$ & $08(100 \%)$ \\
Total & $34(68 \%)$ & $16(32 \%)$ & $50(100 \%)$ \\
\hline
\end{tabular}




\section{DISCUSSION}

The survival rate of ventilated neonates was $68 \%$, though less than that quoted for developed countries (91\%) Riyas PK et al, higher than that quoted for other developing countries (46$54 \%$ ) Nangia $\mathrm{S}$ et al, Kambarami $\mathrm{R}$ et $\mathrm{al}^{11-13}$. Differences in mortality of ventilated neonates between developed and developing countries may be related to the ready availability of surfactant and Total Parenteral Nutrition (TPN) in developed countries as compared to the developing countries. RDS a condition almost exclusively seen in the preterm neonates was the single most common reason for ventilation in the NICU, survival accounting for $77 \%$ of admissions. This finding is similar to other studies, Nangia $\mathrm{S}$ et al \& Mathur NC et al ${ }^{12,14}$. The non-survivors in this study were noted to be the smaller and less mature; this association of low birth-weight and immaturity with poor survival has been documented in other studies, Mathur NC et al \& Herman S et al ${ }^{14,15}$. The value of surfactant in improving outcome of neonates with RDS, decreasing the length of ventilation and decreasing the incidence of some complications has been previously documented in the study of Stahlman MT et $\mathrm{al}^{16}$. Although surfactant is available in this setting it is not accessible to the majority of patients because of cost. Means of increasing accessibility of this drug needs to be explored for the future as in the long term; surfactant use will lead to decreased expenditure.

It is observed that the survival of neonates with RDS increases with increases of BW and GA at initiation of ventilation shown in study of Murdock Al et al, and Northway WH et al ${ }^{17,18}$. Our results are consistent with them. Neonates whose BW was $<1500$ gm and those who required mechanical ventilation before 24 hours of age had reduced chances of survival compared to those with birth weight $>1500 \mathrm{gm}$ and who did not require mechanical ventilation until after $24 \mathrm{hr}$ of age. These results may be related to greater severity of the disease in the former patients. There was a steady increase in survival with increasing birth weight and gestational age. However the survival rates were comparatively lower in neonates with $\mathrm{BW}$ of $<1000 \mathrm{gm}$ and GA $<30$ weeks. The poor survival observed for neonates with BW $<1000 \mathrm{gm}$ is comparable to recent Indian experienced. Pneumonia, sepsis and air leaks were the common complications of mechanical ventilation followed by intracranial hemorrhage and PDA. Pulmonary air leaks were the commonest complication in western countries, Kambarami $\mathrm{R}$ et $\mathrm{al}{ }^{19}$. High peak and mean airway pressures and prolonged inspiratory time are implicated as important factors causing air leaks, Stahlman MT et al ${ }^{16}$. Pulmonary air leaks were, however, uncommon and found only in three neonates. It was often difficult to determine whether complications like pneumonia and air leaks in RDS are related to mechanical ventilation per se or occur as a part of the natural course of the disease. As the complications are important causes of death, early diagnosis and judicious management of these complications is important. Bronchopulmonary dysplasia, a known complication of prolonged ventilation, Northway WH et al, Kambarami R et al, occurred in $6 \%$ patients in this study ${ }^{18-19}$.

Those neonates required HFOV relatively high mortality (69\%) than Conventional ventilation (63\%), as the neonates were very much critical, moribund and had hemodynaminc instability with multiorgan involvement. And also we had only one HFOV, so could not placed the neonates in time due to unavailability.

Another area to be considered is the nutritional needs of the VLBW neonates. Nutrition plays a major role in the survival of these infants and the inability to support them totally with parenteral nutrition is a factor that limits outcome. There is a need for the development of a TPN program in the neonatal unit. Again the results of this study can be used to justify to policy makers the necessity for the inclusion of parenteral nutrition on the hospital formulary.

There is a need for further studies to define predictors of outcome in the VLBW infants, which will guide management protocols and also help in the prevention, identification and management of complications. A perinatal database needs to be established to facilitate tracking of performance of the unit and the conduct of ongoing studies that will provide evidence based data to guide management policies. The judicious use of neonatal intensive care measures in a developing country can result in a reduction of morbidity and mortality. However, to maximize on benefits versus cost in an atmosphere of budgetary constraint, evidence based management policies and protocols must be developed and implemented.

\section{CONCLUSIONS}

Mechanical ventilation reduces the neonatal mortality, hence facilities for neonatal ventilation should be included in the regional and central hospitals providing intensive care for neonates.

\section{DISCLOSURE}

All the authors declared no competing interest. 


\section{REFERENCES}

1. March of Dimes, PMNCH, Save the Children, WHO. Born Too Soon: The Global Action Report on Preterm Birth. Eds CP Howson, MV Kinney, JE Lawn. World Health Organization. Geneva. 2012.

2. Bhutta ZA, Yusuf K, Khan IA. Is management of neonatal respiratory distress syndrome feasible in developing countries? Experience from Karachi (Pakistan). Pediatric Pulmonol. 1999; 27: 305-311.

3. Ghafoor T, Mahmud S, Ali S, Dogar SA. Incidence of respiratory distress syndrome.JColl Surg Pak. 2003; 13: 271-273.

4. Engle WA. The Committee on Fetus and Newborn. Surfactant-Replacement Therapy for Respiratory Distress in the Preterm and Term Neonate. Pediatrics. 2008; 212: 419-423

4. Katz LA, Klein JM. Repeat Surfactant Therapy for Postsurfactant Slump. J Perinatol. 2006; 26: 414-422.

5. Rojas MA, Lozano JM, Rojas MX, Laughon M, Bose CL, Rondon MA et al. Very early surfactant without mandatory ventilation in premature infants treated with early continuous positive airway pressure: a randomized, controlled trial. Pediatrics. 2009; 123: 137-142.

6. Turker G, Koksal N. Complement 4 levels as early predictors of poor response to surfactant therapy in respiratory distress syndrome. Am J Perinatol. 2005; 22:149-154.

7. Fuchs H, Lindner W, Leiprecht A, Mendler MR, Hummler HD. Predictors of early nasal CPAP failure and effects of various intubation criteria on the rate of mechanical ventilation in preterm infants of $<29$ weeks gestational age. Arch Dis Child Fetal Neonatal Ed. 2011; 96: F343-347.

8. Singh GK, Yu SM. Infant mortality in the United States: Trends, differentials, and projections 1950 through 2010. Am J Public Health. 1995;85(7):957-964.

9. Heron M, Sutton PD, Xu J, Ventura SJ, Strobino DM, Guyer B. Annual summary of vital statistics: 2007. Pediatrics. 2010;125(1):4-15.

10. Richardson DK, Gray JE, Gortmaker SL, Goldmann DA, Parsley DM, McCormick MC. Declining severity adjusted mortality: Evidence of improving neonatal intensive care. Pediatrics. 1998; 102: 893-899.

11. Riyas PK, Vijayakumar KM, Kulkarni ML. Neonatal mechanical ventilation. Indian J Pediatr. 2003; 70: 537-540.

12. Nangia S, Saili A, Dutta AK, Gaur V, Singh M, Seth A et al. Neonatal mechanical ventilation experience at a level II care centre. Indian J Pediatr. 1998; 65: 291-296.

13. Kambarami R, Chidede O, Chirisa M. Neonatal intensive care in a developing country: Outcome and factors associated with mortality. Cent Afr J Med. 2000; 46: 205-207.

14. Mathur NC, Kumar S, Prasanna AL, Sahu UK, Kapoor R, Roy S et al. Intermittent positive pressure ventilation in a neonatal intensive care unit: Hyderabad experience. Indian Pediatr. 1998; 35: 349-352.

15. Herman S, Reynolds EOR. Mehtods for improving oxygenation in infants mechanically ventilated for severe hyaline membrane disease. Arch Dis Child. 1973, 48: 612-617.

16. Stahlman MT, Malan AF, Shepard FM et al. Negative pressure assisted ventilation in infants with hyaline membrane disease. J Pediatr. 1970; 76: $174-182$.

17. Murdock Al, Linsao I, Reid MM et al.Artificial mechanical ventilation in the respiratory distress syndrome. A controlled trial. Arch Dis Child. 1970; 45:624-633.

18. Northway WH, Rosen RC, Porter DY. Pulmonary disease following respiratory therapy of hyaline mebrane disease: Broncho pulmonary dysplasia. New Eng J Med. 1967; 276: 357-359.

19. Kambarami R, Chidede O, Chirisa M. Neonatal intensive care in a developing country: Outcome and factors associated with mortality. Cent Afr J Med. 2000; 46: 205-207. 